\title{
Comparative analysis between locking compression plate and Joshi's external stabilization system in the management of proximal tibial fractures
}

\author{
Amit Dwivedi, Anupinder Sharma*, Vaibhav Ashta, Robium Nairobi, Sunandan Nandi
}

Department of Orthopedics, Santosh Medical College, Ghaziabad, Uttar Pradesh, India

Received: 17 August 2020

Revised: 30 September 2020

Accepted: 31 October 2020

\author{
*Correspondence: \\ Dr. Anupinder Sharma, \\ E-mail: anupinder.sharma@gmail.com
}

Copyright: (C) the author(s), publisher and licensee Medip Academy. This is an open-access article distributed under the terms of the Creative Commons Attribution Non-Commercial License, which permits unrestricted non-commercial use, distribution, and reproduction in any medium, provided the original work is properly cited.

\begin{abstract}
Background: Proximal tibial fractures present with a variety of patterns. They are mostly treated using plate osteosynthesis or Joshi's external stabilization system (JESS) depending upon the injury configuration and surgeon preference. We have compared the efficacy of plate fixation to JESS in the treatment of complex proximal tibial fractures.

Methods: 36 patients of proximal tibial fractures with a mean age of 47 years were included in the study, 20 were treated using plate osteosynthesis while the other 16 were treated using JESS, they were followed up at regular intervals till 24 weeks and the progress was recorded in accordance with the knee society score (KSS) parameters

Results: 20 patients were treated using plate osteosynthesis, 18 of them had excellent KSS scores, 2 patients recorded good scores, average range of flexion was $126^{\circ}$, no incidences of superficial or deep infections were seen in any of them. Bone consolidation was achieved around 12 weeks in plate fixation group of the16 patients treated using JESS, 12 had excellent scores, 4 recorded a good score, average range of flexion was $118^{\circ}$, superficial infection was seen in 2 patients, with no incidence of deep infection. Bone consolidation was achieved around 16 weeks in JESS group.

Conclusions: Both open reduction internal fixation (ORIF) with plating and JESS appear to be adequate fixation methods for complex proximal tibial fractures, but as per our study plate fixation resulted in earlier bone consolidation and gave a slightly better functional outcome compared to JESS.
\end{abstract}

Keywords: Locking compression plate, JESS, Schatzker, KSS

\section{INTRODUCTION}

Proximal tibial fractures make for only $1 \%$ of all adult fractures, but approximately $90 \%$ of these are intra articular, making them one of the commonest intra articular fractures in adults. ${ }^{1,2}$ They result from direct axial loading or indirect valgus/varus forces and present with a wide variety of patterns with different degrees of displacement, articular surface depression predominantly with the involvement of either the medial or lateral or both tibial condyles along with a varying degree of soft tissue trauma viz skin, ligaments and meniscus injury. ${ }^{1,3}$
As the goal of treatment in these fractures is anatomic restoration of articular surface to prevent post traumatic degenerative joint disease ORIF with a locking compression plate (LCP) holds merit but as early surgery and preservation of the soft tissue is also necessary to permit healing, an external fixator like the JESS also has its merits. ${ }^{4-7}$

In our study we have made an attempt to compare the efficacy of ORIF with plating and JESS in the treatment of proximal tibial fractures with respect to the variables of time of union, post op complications and the KSS which 
includes the parameters of pain, range of motion, stability, alignment, extension lag in the post op period of 6 months. ${ }^{8}$

\section{METHODS}

A total of 36 patients of isolated proximal tibial fractures were operated in the orthopedics department at Santosh hospital, Ghaziabad from November 2018 to December 2019. Only closed fractures (Schatzker type 1 to type 6); (Gustilo-Anderson type 1) were included in the study.,9 Open fractures Gustilo Anderson type 2 and type 3, pathological fractures and patients with severe comorbidities were excluded from the study. There were 20 men and 16 women with a mean age of 40 years whose consent in their known language approving their inclusion into our study was taken before initiation of data collection. Out of the 36 patients, 28 had sustained the injury due to a high velocity trauma, rest 8 patients sustained fracture due to trivial trauma.

The treatment method viz the locking plate and JESS was chosen on the basis of the type of fracture, the amount of displacement, amount of articular surface depression and the condition of the skin surrounding the tibial plateau. ${ }^{4,5}$

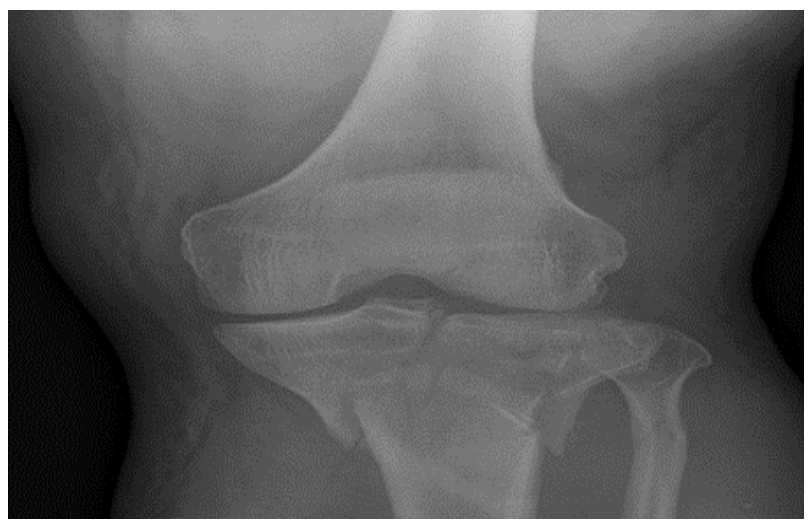

Figure 1: Antero-posterior radiograph of a complex tibial plateau fracture (Schatzker V).

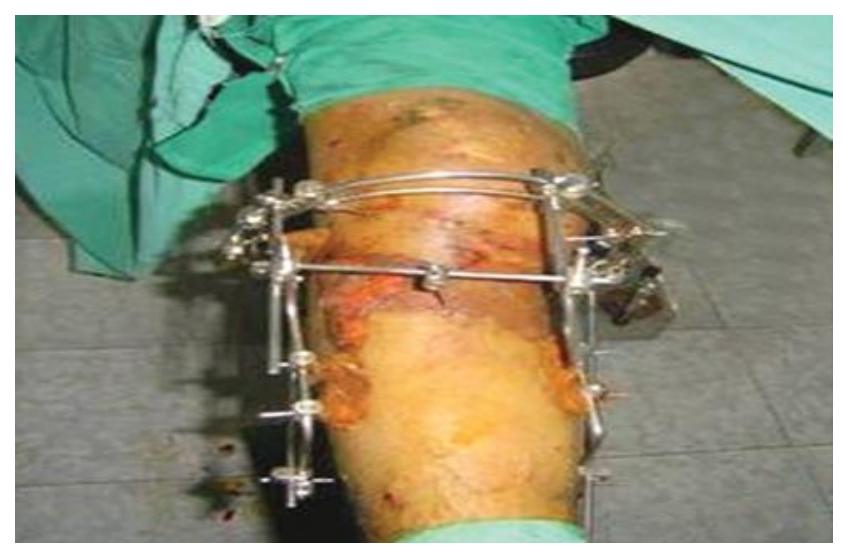

Figure 2: Patient with a complex tibial fracture of blisters poor soft tissue condition, managed using JESS.

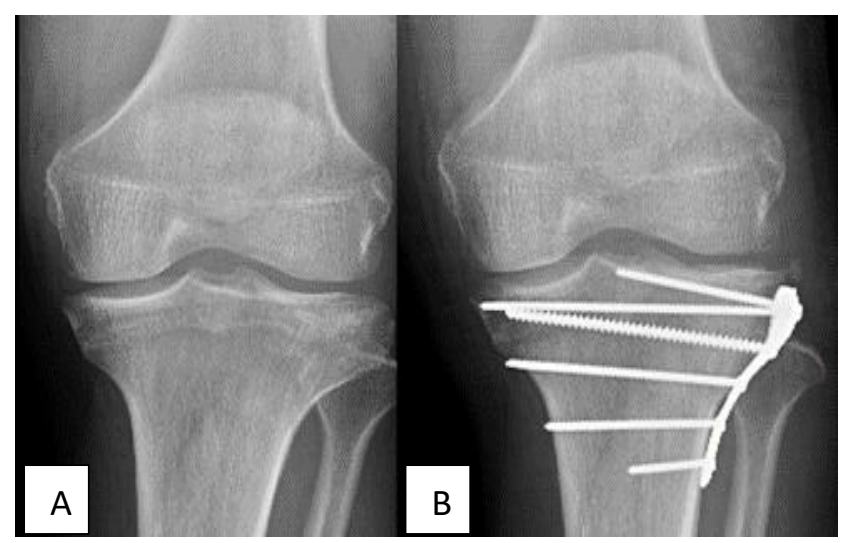

Figure 3: Antero-posterior and lateral radiograph of a depressed fracture of the lateral condyle managed using ORIF using an LCP.

In the other 16 patients closed reduction was done on a fracture table using ligamentotaxis under fluoroscopic control. $2 \mathrm{~mm}$ guide wires inserted $10 \mathrm{~mm}$ distal and parallel to the joint line were used to hold the articular surface reduction followed by the placement of the JESS frame

A total of 20 patients were chosen based on their injury profile for ORIF with locking plate. All the surgeries were performed using a lateral and an anterolateral approach with the application of a single lateral locking plate. An immediate post op X-ray was done followed by X-rays at subsequent follow ups at 6, 12, 18 and 24 weeks. Gentle quadriceps exercises were allowed after a period of 48 hours and the patients were encourage to move their knee in the 0 to 20-degree arc up to a 7-day period, after which passive motion was increased to 50-degree. By day 12 post op sutures were removed and the patient was allowed to move the knee into a 90-degree flexed position. Non weight bearing crutches were used for a period of 6 weeks and full weight bearing was allowed in the 12-16-week period after signs of radiological fracture union.

An immediate post op X-ray was done followed by X-rays at subsequent follow up visits at $6,12,18$ and 24 weeks.

Static quadriceps exercises were started from the first post op day, mobilization exercises were encouraged as tolerated to achieve full range of motion as early as possible. Partial weight bearing was delayed till about 78-weeks and in 14-18-week period full weight bearing was allowed with removal of the JESS frame post signs of radiological union.

Patients were followed up for complications, union time and the functional outcome was evaluated using the American KSS which takes into account the parameters of post op pain, range of motion, stability, alignment, presence of flexion contractures and extension lag. ${ }^{8}$

The data was analyzed using the IBM SPSS statistics software which was collected after getting an approval for 
a human subject research proposal from the ethics committee at Santosh university.

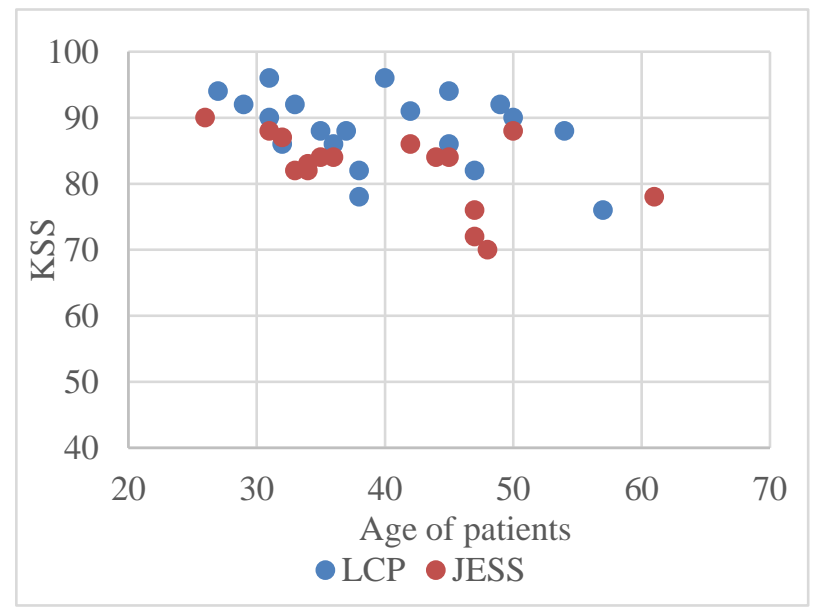

Figure 4: A linear graph of the age specific KSS of plate fixation and JESS. Scores above 80 are considered excellent, above 60 are considered good.

\section{RESULTS}

In this study a total of 36 patients were operated, 20 males and 16 females; 28 of which had incurred the injury due to a road traffic accident, the rest of the 8 patients reported falling from height as the cause of injury.

Based on the characteristics of the fracture and the condition of the surrounding skin, 20 were treated via open reduction and internal locking plate fixation while the other 16 fractures were stabilized using a JESS.

\section{Patients treated using ORIF with LCP: 20 patients}

The average time between admission and day of surgery was 3 days. No intra operative complications occurred during any of the procedures. The mean duration from surgery to discharge was 5 days. The patients were followed up at 12,18 and 24 weeks for pain, stability, knee ROM and alignment.

On the 24-week follow-up, 16 patients were able to walk comfortably and reported no pain, 3 could walk up to 60 mins without discomfort, 1 patient could walk less than 30 mins. 15 patients had a normal range of motion on followup, while the other 5 had a range of motion above 90 degree. Flexion contracture of more than 10 degree was seen in 2 patients, while the other 18 had no flexion contracture. Extension lag was not reported in 19 patients, while 1 patient had a lag of between 10 to 20 degree. Varus malalignment of between 0 to 4 degrees was seen in 1 patient, while normal alignment was seen in the other 19 patients.

Full weight bearing was achieved at $12^{\text {th }}$ week in 16 patients, while the other 4 were able to bear full weight in the $18^{\text {th }}$ week post-op. No complications of deep infection, hardware instability, early hardware removal post op foot drop was seen in any patient. The results have been summarized in the table 1 using the $\mathrm{KSS}^{8}$ As per the scoring, the maximal being 100; excellent results were seen in 18 patients (score above 80 ), 2 patients had a good score (between 60 and 80), no patients had an average or poor score.

\section{Patients treated with JESS: 16 patients}

The average time between admission and surgery was 4 days, no significant intra op complications were encountered during the procedure. The average duration between surgery and discharge was 5 days. JESS frame was removed at 6-8 weeks post op, depending on the clinical and radiological signs of union. The patients were followed up at 12, 18 and 24 weeks for pain, stability, knee ROM and alignment.

On 24 weeks of follow up 11 could walk comfortably and reported no pain, 5 could walk for more than 60 minutes and reported mild pain on prolonged walking and climbing the stairs. The ROM was normal in 10 patients, while 6 had a ROM above 90 degree. 13 patients had less than 5 $\mathrm{mm}$ of AP instability, 14 had less than $5 \mathrm{~mm}$ of mediolateral instability. Flexion contracture was seen in 4 patients of between 10 to 15 degree. Extension lag of between 10-20 degrees was seen in 3 patients. Pin tract infection was noted in 2 patients, while construct stability was maintained in all but 1 . Incidences of deep infections, early hardware removal, post op foot drop or compartment syndrome were nil. Full weight bearing was achieved in the $14^{\text {th }}$ week period by 6 patients, 9 patients were able to bear full weight in the $16^{\text {th }}$ week period while 1 patient achieved it in the $20^{\text {th }}$ week.

The results have been summarized in the table 2 using the KSS. ${ }^{8}$ As per the score, excellent results were seen in 12 patients, while 4 patients had a good score. No patients were marked average or poor in the scoring.

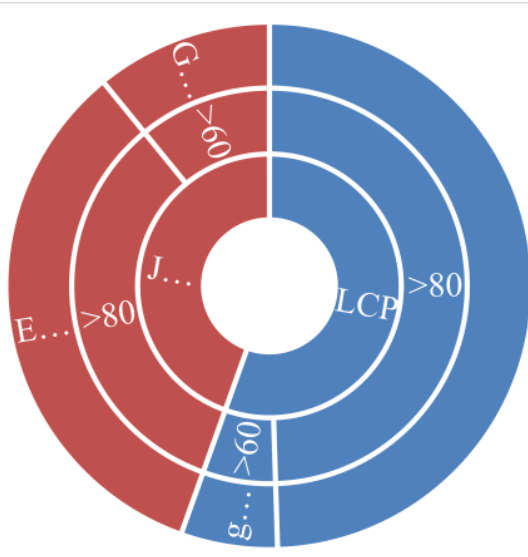

Figure 5: A pie chart of the comparison of patients treated using LCP and JESS along with the

distribution of patients achieving excellent and good scores with the respective treatment methods. 
Table 1: Distribution of patients as per the parameters used in the KSS for patients treated using LCP.

\begin{tabular}{|c|c|c|c|c|c|c|}
\hline \multirow{2}{*}{$\begin{array}{l}\text { Criteria } \\
\text { Additive scores }\end{array}$} & \multicolumn{3}{|c|}{ Grading } & & & \multirow[b]{3}{*}{ Severe } \\
\hline & & & & & & \\
\hline \multirow[t]{2}{*}{ Pain } & \multirow[t]{2}{*}{ None } & \multicolumn{2}{|l|}{ Mild } & & Moderate & \\
\hline & & Stairs only & Walking/stairs & Occasional & Continuous & \\
\hline \multirow{3}{*}{$\operatorname{ROM}\left(5^{\circ}=1\right.$ point $)$} & 16 & 2 & 2 & 0 & 0 & \\
\hline & $135^{\circ}$ & $>90^{\circ}$ & & $<90^{\circ}$ & & \\
\hline & 15 & 5 & & 0 & & \\
\hline \multicolumn{7}{|l|}{ Stability } \\
\hline \multirow{2}{*}{ Antero-posterior } & $<5 \mathrm{~mm}$ & $5-10 \mathrm{~mm}$ & & $>10 \mathrm{~mm}$ & & \\
\hline & 19 & 1 & & 0 & & \\
\hline \multirow{2}{*}{ Medio-lateral } & $<5 \mathrm{~mm}$ & $6-9 \mathrm{~mm}$ & & $10-14 \mathrm{~mm}$ & & $>15 \mathrm{~mm}$ \\
\hline & 18 & 2 & & 0 & & 0 \\
\hline \multicolumn{7}{|l|}{ Deduction scores } \\
\hline \multirow{2}{*}{ Flexion contracture } & $<10^{\circ}$ & $10-15^{\circ}$ & & $15-20^{\circ}$ & & $>20^{\circ}$ \\
\hline & 18 & 2 & & 0 & & 0 \\
\hline \multirow{2}{*}{ Extension lag } & $<10^{\circ}$ & $10-20^{\circ}$ & & $>20 o$ & & \\
\hline & 19 & 1 & & 0 & & \\
\hline \multirow{2}{*}{$\begin{array}{l}\text { Alignment } \\
\left(1^{\circ}=3 \text { points }\right)\end{array}$} & $5-10^{\circ}$ varus & $0-4^{\circ}$ valgus & & $11-15^{\circ}$ valgus & & \\
\hline & 19 & 1 & & 0 & & \\
\hline
\end{tabular}

Table 2: Distribution of patients as per the parameters used in the KSS for patients treated using JESS.

\begin{tabular}{|c|c|c|c|c|c|c|}
\hline Criteria & & & ading & & & \\
\hline Additive scores & & & & & & \\
\hline Pain & None & Mild & & Moderate & & Severe \\
\hline & & Stairs only & Walking/stairs & Occasional & Continuous & \\
\hline & 11 & 2 & 2 & 1 & 0 & \\
\hline $\operatorname{ROM}\left(5^{\circ}=1\right.$ point $)$ & $135^{\circ}$ & $>90^{\circ}$ & & $<90^{\circ}$ & & \\
\hline & 10 & 6 & & 0 & & \\
\hline Stability & & & & & & \\
\hline Antero-nesterior & $<5 \mathrm{~mm}$ & $5-10 \mathrm{~mm}$ & & $>10 \mathrm{~mm}$ & & \\
\hline Antero-posterior & 13 & 3 & & 0 & & \\
\hline Medio-lataral & $<5 \mathrm{~mm}$ & $6-9 \mathrm{~mm}$ & & $10-14 \mathrm{~mm}$ & & $>15 \mathrm{~mm}$ \\
\hline Vledio-lateral & 14 & 2 & & 0 & & 0 \\
\hline Deduction scores & & & & & & \\
\hline Flevion contracture & $<10^{\circ}$ & $10-15^{\circ}$ & & $15-20^{\circ}$ & & $>20^{\circ}$ \\
\hline Flexion contracture & 12 & 4 & & 0 & & 0 \\
\hline Fytoncion loa & $<10^{\circ}$ & $10-20^{\circ}$ & & $>20^{\circ}$ & & \\
\hline Extension lag & 13 & 3 & & 0 & & \\
\hline Alignment & $5-10^{\circ}$ varus & $0-4^{\circ}$ valgus & & $11-15^{\circ}$ valgus & & \\
\hline$\left(1^{\circ}=3\right.$ points $)$ & 12 & 2 & & 0 & & \\
\hline
\end{tabular}

\section{DISCUSSION}

Proximal tibia fractures present with a spectrum of soft tissue and bony injuries that can produce permanent disability. They are caused by a variety of mechanism most commonly due to high energy trauma. They present with complex fracture patterns with fracture communication, fragment displacement and associated soft tissue injuries internally and externally which present a multifaceted problem of difficulty in achieving joint congruity, limb alignment, knee stability and a functional range of knee motion. ${ }^{12}$
The prognosis of these fractures depends upon the degree of articular depression the extent of condylar fragment separation, diaphyseal-metaphyseal comminution and the condition of the surrounding ligaments and soft tissue envelope.

Conservative management of these injuries have mostly yielded unsatisfactory results due to the major limitations of inadequate reduction of articular surface and ineffective limb alignment control associated with non-operative treatment. ${ }^{3,10,11}$

The incidence of these fractures is increasing due to the increase of motor vehicles, and adequate treatment of any 
injury around the knee is of paramount importance because failing to do so will impart significant morbidity to the patient and affect their quality of life. ${ }^{1}$

Thus, on the surface open reduction and internal fixation with a plate appears to be the treatment of choice as it covers the limitations of conservative management but open wounds or extensive closed soft tissue injuries add to the challenges in adopting an open procedure, which is when a JESS is more appropriate.

In our study we have attempted to do a comparison of both these techniques in a group of 36 patients that presented to us with a varied degree proximal tibial injury and soft tissue damage.

The study included 26 males and 10 females, indicating a male preponderance of the said fracture. $85 \%$ of the patients belonged to the 30-50 years age group which indicates these fractures occur more commonly in the actively earning age group. Similar observations of average age have been made by Duvelius et al average age 48 years, by Porter study- average age 47 years. ${ }^{13,14}$

Road traffic accident was the most common cause of injury (75\%), followed by a fall from height $(20 \%)$ and fall while playing a sport (5\%). Chaix et al reported similar results with $71 \%$ cases due to RTA, $16 \%$ due to fall from height and $1 \%$ as a sports injury. ${ }^{15}$

Based on the study, as per the KSS; open reduction and plating gave excellent score in $90 \%$ patients. Similar results have been published by Chaix et al $86 \%$ excellent to good scores in patients managed by surgical means. ${ }^{15}$ Burri et al reported $89 \%$ excellent to good results, while Tschene reported $77 \%$ fractures treated by surgical means to give good results. ${ }^{16,17}$

In the patients treated using a JESS, excellent score was seen in $75 \%$ patients. Similar results were reported by Babis et al in their study of high energy tibial plateau fractures treated with an external fixator, with $85 \%$ patients having good to excellent results. ${ }^{18}$ Kataria et al in their study using small wire external fixator with beaded olive wires, reported $94.7 \%$ good to excellent results. ${ }^{6}$ Muhammad et al, have reported $81.8 \%$ good to excellent results in high energy tibial plateau fractures treated using Illizarov ring fixator and beaded olive wires. ${ }^{19}$

On comparative analysis, none of the patients treated using ORIF or JESS reported average or poor results, but ORIF with plating gave slightly better results than the JESS (90\% excellent score vs $75 \%$ excellent score).

Bony consolidation occurred earlier in the plate fixation group $\sim 12$ weeks to the JESS group $\sim 16$ weeks, which is in accordance with the comparative case control study done by Berven et al and by the study done by Krupp et al describing a decreased time to union after plate fixation of bicondylar tibial fractures compared to an external fixator. ${ }^{20,21}$

No incidence of deep infection or deep venous thrombosis were seen in any of the patients, while superficial PIN tract infection was seen in 2 patients treated with the JESS, which is in agreement with the study done by Babis et al who reported a $9.1 \%$ pin tract infection rate. ${ }^{18}$

\section{CONCLUSION}

Both ORIF with plating and JESS appear to be adequate fixation methods for complex proximal tibial fractures, but as per our study plate fixation resulted in earlier bone consolidation and gave a slightly better functional outcome compared to JESS. The patients were able to initiate earlier range of motion exercises with plate fixation and achieved a higher mean range of motion at 24 weeks follow up compared to the JESS group by 8 degrees. JESS was successful as a fixation method in skin compromised patients but also resulted in a $10 \%$ incidence of superficial infection post fixation.

Funding: No funding sources

Conflict of interest: None declared

Ethical approval: The study was approved by the institutional ethics committee

\section{REFERENCES}

1. Court-Brown CM, Caesar B. Epidemiology of adult fractures: a review. Injury. 2006;37:691-7.

2. Naik MA, Arora G, Tripathy SK, Sujir P, Rao SK. clinical and radiological outcome of percutaneous plating in extra articular proximal tibial fractures; a prospective study. Injury. 2013;44(8):1081-6.

3. Schatzker J, McBroom R, Bruce D. The tibial plateau fractures. The Toronto experience 1968-1975. Clin Orthop Relat Res. 1979;138:94-104.

4. Wagner M. General principles for the clinical use of the LCP. Injury. 2003;34:B31-42.

5. Zahid M, Sherwani MKA, Siddiqui YS, Abbas M, Asif N, Sabir AB. The role of JESS fixator in the management of tibial plateau fractures which are associated with severe soft tissue injuries. J Clin Diagn Res. 2010;4:3356-61.

6. Kataria H, Sharma N, Kanojia RK. Small wire external fixation for high-energy tibial plateau fractures. J Orthop Surg. 2007;15:137-43.

7. Subhasi M, Kapukaya A, Arslan H, Ozkul E, Cebesoy O. Outcome of open comminuted tibial plateau fractures treated using an external fixator. J Orthop Sci. 2007;12:347-53.

8. Martimbianco ALC, Calabrese FR, Iha LAN, Petrilli M. Reliability of the American Knee Society Score. Acta Ortop Bras. 2012;20(1):34-8.

9. Kim PH, Leopold SS. Gustilo Anderson Classification. Clin Orthop Relat Res. 2012;407(11):3270-4. 
10. Blokker CP, Rorabeck PB, Tibia plateau fractures-An analysis of the result of treatment in 60 patients. Clin Orthop. 1984;182:193-8

11. Drennan DB, Locher FG, Maylahn DJ. Fractures of the tibial plateau: Treatment by closed reduction and spica cast. JBJS. 1979;61;989-5.

12. Jiangr, Luo CF, Zeng BF. Biomechanical evaluation of different fixation methods for fracture dislocation involving the proximal tibia. Clin Biomech. 2008;23:1059-64.

13. Duvelius PJ, Conolly JF. Closed reduction of the tibial plateau fracture. A comparison of functional and roentgenographic end results. Clin Orthop.1988;230:116-25.

14. Porter BB. Crush fractures of the lateral tibial condyle. Factors influencing the prognosis. JBJS. 1970;52:676.

15. Chaix. Fractures of the tibial plateau. In: Insall JN, Winsdor RE, Scottw, editors. Surgery of the knee. $2^{\text {nd }}$ Edition. New York: Churchill Livingstone. 1993:1038.

16. Burri C, Bartzle G, Coldway J. Fractures of the tibial plateau. Clin Orthop. 1979;138:84-93.

17. Tscherne H, Lobenhoffer P. Tibial plateau fractures, management and expected result. Clin Orthop. 1993;292:87-100.
18. Babis GC, Evangelopoulos DS, Kontovazenitis P, Nikolopoulos K, Soucacos PN. High energy tibial plateau fractures treated with hybrid external fixator. J OrthopSurge Res. 2011;6:35-41.

19. Muhammad AK, Muhammad IK, Muhammad S. Management of complex tibial plateau fractures with Illizarov Fixator. Pak J Surg. 2012;28:110-13.

20. Berven et al. Comparing case control study for treatment of proximal tibia fractures with a complete metaphyseal component in two centres with distinct strategies: fixation with illizarov frame or locking plate. J Orthop Surg Res. 2018;13:121.

21. Kruppe RJ, Malkani AL, Roberts CS, Seligson D, Crawford $\mathrm{CH}$. Treatment of bicondylar tibial plateau fractures using locking plate versus external fixation. Orthoaedics. 2009;32(8):5242-4.

Cite this article as: Dwivedi A, Sharma A, Ashta V, Nairobi R, Nandi S. Comparative analysis between locking compression plate and Joshi's external stabilization system in the management of proximal tibial fractures. Int J Res Orthop 2021;7:56-61. 